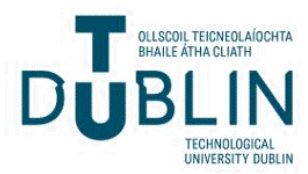

Technological University Dublin

ARROW@TU Dublin

\section{Optimal Sizing of Energy Storage with Embedded Wind Power Generation}

\author{
Nicholas Roche \\ Technological University Dublin \\ Jane Courtney \\ Technological University Dublin, jane.courtney@tudublin.ie
}

Follow this and additional works at: https://arrow.tudublin.ie/engscheleart2

Part of the Electrical and Electronics Commons, and the Power and Energy Commons

\section{Recommended Citation}

N. Roche and J. Courtney, "Optimal Sizing of Energy Storage with Embedded Wind Power Generation," 2020 55th International Universities Power Engineering Conference (UPEC), Torino, Italy, 2020, pp. 1-6, doi: 10.1109/UPEC49904.2020.9209807.

This Conference Paper is brought to you for free and open access by the School of Electrical and Electronic Engineering at ARROW@TU Dublin. It has been accepted for inclusion in Articles by an authorized administrator of ARROW@TUDublin. For more information, please contact arrow.admin@tudublin.ie, aisling.coyne@tudublin.ie,gerard.connolly@tudublin.ie. Funder: School of Electrical \& Electronic Engineering

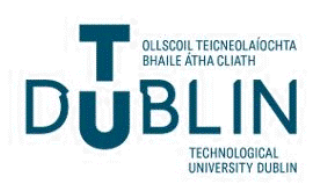




\title{
Optimal Sizing of Energy Storage with Embedded Wind Power Generation
}

\author{
Nicholas Roche, Jane Courtney \\ School of Electrical \& Electronic Engineering \\ Technological University Dublin \\ Dublin, Ireland \\ C16348626@myTUDublin.ie
}

\begin{abstract}
Energy storage technologies are key to increased penetration of renewable energies on the distribution system. Not only do they increase availability of energy, but they contribute to the overall reliability of the system. However, the cost of large-scale storage systems can often be prohibitive, and storage needs to be sized appropriately, both to fill the energy gaps inevitable in renewable energies such as wind and to minimize costs. In this work, a Monte Carlo Simulation is performed to optimally size an energy storage system while minimizing overall system cost. 30 years of historical wind speed data are used to model the probabilistic behaviour of the wind and the seasonal variation of the wind is captured in the model. A generation adequacy assessment shows the system reliability increasing with energy storage. The energy storage is sized for reliable operation of the case study system with $60 \%$ wind penetration. The levelized cost of storage is calculated for the optimally sized level of storage and for the level of storage required to make wind power generation reliable.
\end{abstract}

Keywords- Embedded Generation, wind power, energy storage, reliability.

\section{INTRODUCTION}

Member states of the European Union as well as many countries across the world have joined in an effort to decarbonise energy production. Renewable Energy Sources (RES) have continued to mature and are now cost-competitive with other forms of conventional generation. Wind power generation is one of the most common forms of RES but the intermittent nature of wind power generation makes it difficult to forecast and negatively impacts system stability [1] [2]. The use of Energy Storage Systems (ESS) to compensate for the stochastic generation from Wind Turbine Generators (WTGs) is widely acknowledged as a potential solution. Studies on the integration of renewables in the US showed that only up to $20 \%$ penetration could be accommodated without energy storage [3].

The case study presented here focuses on Embedded Renewable Generation (ERG) in a rural network in Ireland. In Ireland, wind power generation is the most common form of Embedded Renewable Generation (ERG), accounting for more than $85 \%$ of electricity generated form renewables. Often wind farms are installed in remote coastal areas where the network is not strong and struggles to accommodate this type of generation. With wind power generation exceeding $20 \%$ in Ireland [4], the need for ESS should be investigated especially given our small geographical area and relatively poor interconnection capacity with larger electricity markets.

One of the most recent comprehensive literature surveys on the topic of ESS used with ERG indicated that no single ESS technology stands out when all technical characteristics are considered [5]. Different ESS technologies are suited to different applications [6] and can be roughly classified into two categories dictated by the duration they can operate for: short-term (Power services) and long-term (Energy services). In a more recent study, battery storage technologies were found to be some of the most popular and mature [7].

The most prevalent analysis technique in the literature [814] is Optimal Power Flow (OPF). This method yields the most accurate results but it is complex and requires a great deal of data relating to the power system, the underlying control systems and market operation [15]. Comprehensive techno-economic assessments of the use of ESS in a renewable-energy-rich system and the interaction with the EU Single Energy Market can be performed using OPF [9] when such data is fully available.

However, many studies have found the economic effects of increased reliability of the power system can also be a helpful metric for assessing the benefits of storage [9] [16]. A wider range of benefits can also be determined through reliability studies [2]. The relationship between ESS capacity and improved reliability is investigated here, with the ESS colocated with a WTG, in the form of a generation adequacy assessment. The main task is to optimally size the ESS to compensate for the variable output of the WTG while minimising the overall cost of the system. This involves appropriately valuing the economic damage to customers, from power outages due to poor reliability, which will be modelled by a Composite Customer Damage Function (CCDF). The CCDF is then used to calculate the Value of Lost Load (VoLL) which reflects the economic cost of power outages to the customers. The VoLL is equivalent to the Expected Cost [11]. This CCDF will be used in the Monte Carlo Simulation (MCS) to simulate the more dynamic components of the system: the WTG \& ESS interaction with the load. In the case study, 30 years of historical wind speed data are used to model the stochastic behaviour of the wind. The simulation period is over the entire year, 8760 hours, leap days are omitted for consistency.

Location-specific factors that influence the optimum ESS capacity can be identified as well as the sensitivity to the models and data used [12]. Here, a case study is performed on a rural area of County Kerry, Ireland.

\section{SYSTEM MODELLING}

The network is simplified to a single bus system for the purposes of evaluating the generation adequacy. The system losses, mean time to failure and forced outage rate of components are investigated in the full reliability study.

\section{A. Wind Speed Model}

Historical hourly wind speed data, measured at $10 \mathrm{~m}$ height, were used to model the behaviour of the wind. The wind speed data were adjusted to the height of the WTG tower hub using the shear function [13]: 


$$
v=v_{0} *\left(\frac{H}{H_{0}}\right)^{n}
$$

where $\mathrm{v}_{0}$ is the wind speed at the measured height $\left(H_{0}\right) ; v$ is the equivalent wind speed at the height of $H, n$ is a constant adjusting for locational factors. The standard value of 0.143 is used for $\mathrm{n}[14]$.

The Weibull distribution is especially suitable for wind [15] [17] and by creating a distribution for each hour of the year, the relationship between one hour and the next is better captured in the model. The hourly data were fitted to Weibull probability distributions which are simply described by two parameters: scale $(\mathrm{C})$ and shape $(\mathrm{K})$.

\section{B. Wind Turbine Generator}

The power output of the WTG for a given wind speed $(u)$ is given by

$$
P w=\left\{\begin{array}{cc}
0 & \text { if } u_{f} \leq u<u_{c} \\
a+b * u^{K} & \text { if } u_{c} \leq u<u_{r} \\
P r & \text { if } u_{r} \leq u<u_{f}
\end{array}\right.
$$

where variables ' $a$ ' and ' $b$ ' are defined as:

$$
a=\frac{P r * u_{c}^{K}}{u_{c}^{K}-u_{r}^{K}} \quad b=\frac{P r}{u_{c}^{K}-u_{r}^{K}}
$$

$\mathrm{u}_{\mathrm{c}}$ is the cut-in speed (power production starts); $u_{r}$ is the rated wind speed (rated power being produced); $u_{f}$ is the furling wind speed (speed at which the turbine is shut down to prevent structural damage); $\mathrm{Pr}$ is the rated power output of WTG; K is the shape parameter of wind input.

\section{Energy Storage System}

The ESS model used in the MCS is a simple model using the energy capacity $\left(\mathrm{E}_{\mathrm{ESS}}\right)$, power capacity $\left(P_{E S S}\right)$, State of Charge (SoC), and charge / discharge efficiencies. Once identified, the suitable ESS technologies' efficiencies can be incorporated into the model. The power capacity of the ESS $\left(P_{E S S}\right)$ is calculated in (15).

\section{Distribution Network Model}

As a network model for assessing the share of each sector (residential, small industrial, agricultural, commercial) of the total, composite load this paper uses the rural distribution network attached to Bus 6 of the Roy Billinton Test System (RBTS). The RBTS is widely used in the literature [11] [16].

\section{E. Load Profile}

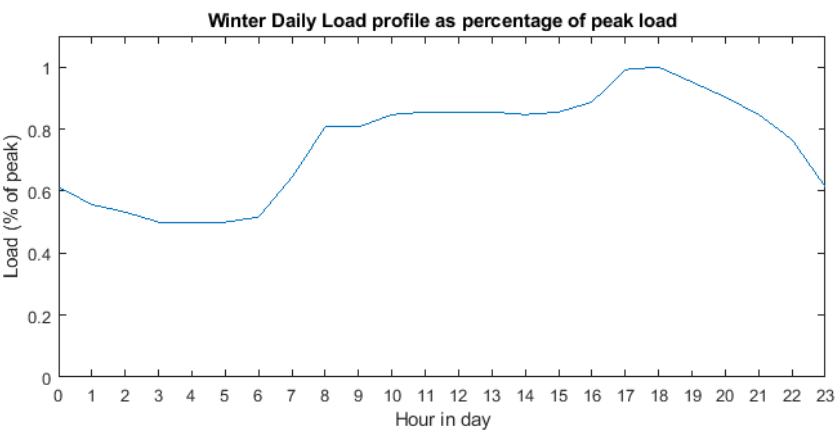

Fig. 1. National average winter load profile

As a more comprehensive dataset for the case study could not be found, the load profile was derived from the national average [4] for the winter season. Using the winter load profile represents the worst-case scenario as the load fluctuates the most in a typical winter day. The combined peak load for the loads on the network can be calculated and applied to this profile (Fig. 1). This method is seen in [18] [19] [6].

\section{F. Customer Damage}

Customers from different sectors incur different costs when there is a power outage. To derive a combined / composite load the average power consumptions by each sector should be used [20]. Taking the data from Bus 6 of the RBTS, the load composition was developed for a rural network as seen in Table I.

The customer damage versus outage duration for each sector were obtained from [21] and [22] and converted from their respective currency at the time to the equivalent $2020 €$ value. The load composition seen in Table I is used for weighting the calculation of the Composite Customer Damage Function (CCDF) presented in Table II. Values between and beyond the durations specified were extrapolated.

TABLE I. COMPOSITION OF RBTS Bus 6 LOAD

\begin{tabular}{|c|c|c|c|}
\hline \multicolumn{4}{|c|}{ Sector \% of load } \\
\hline Residential & Commercial & Small Industrial & Agricultural \\
\hline 41 & 8.76 & 23.72 & 26.51 \\
\hline
\end{tabular}

TABLE II. CUSTOMER DAMAGE By SECTOR

\begin{tabular}{|c|c|c|c|c|c|}
\hline $\begin{array}{c}\text { Outage } \\
\text { Duration } \\
(\text { hours })\end{array}$ & $\begin{array}{c}\text { Resi- } \\
\text { dential } \\
(\boldsymbol{\epsilon} / \mathbf{k W})\end{array}$ & $\begin{array}{c}\text { Commercial } \\
(\boldsymbol{\epsilon} / \mathbf{k W})\end{array}$ & $\begin{array}{c}\text { Small } \\
\text { Industrial } \\
(\boldsymbol{\epsilon} / \mathbf{k W})\end{array}$ & $\begin{array}{c}\text { Agri- } \\
\text { culture } \\
(\boldsymbol{\epsilon} / \mathbf{k W})\end{array}$ & $\begin{array}{c}\text { Composite } \\
(\boldsymbol{\epsilon} / \mathbf{k W})\end{array}$ \\
\hline 1 & 0.643 & 11.402 & 12.112 & 0.865 & 4.365 \\
\hline 4 & 6.551 & 41.752 & 33.547 & 2.752 & 15.033 \\
\hline 8 & 20.918 & 110.666 & 74.403 & 5.493 & 37.383 \\
\hline 24 & 83.672 & 147.186 & 98.956 & 7.305 & 72.623 \\
\hline
\end{tabular}

\section{ANALYSIS METHOD USED}

The preliminary results from the MCS are used to suggest which ESS technologies would be suitable to match the power and duration of the energy shortages of the system. Then an economic analysis is done to appropriately cost specific ESS technologies. Further sensitivity analyses can be done to assess the impact of varying the wind penetration levels and the impact of ESS costs and VoLL to the optimum ESS capacity.

\section{A. Monte Carlo Simulation (MCS)}

The MCS simulates the dynamic, stochastic operation of the WTG, ESS and aggregated load. It is worth noting that the ESS SoC is set to $50 \%$ at the start of the simulation. By simulating over a large number of years, the variations are averaged out to give reliable results. In the MCS the Value of Lost Load (VoLL) is calculated using the CCDF from Table II, then for outages more than 24 hours an extrapolated function is formed:

$V o L L=\left\{\begin{array}{lr}C C D F(D) * P l(i) & \text { if } 0<D \leq 24 \\ (2.203 * D+19.763) * P l(i) & \text { if } D>24\end{array}\right.$

where $D$ is the outage duration and $P l(i)$ is load for hour $i$.

Also calculated in the MCS, the Loss of Load Probability (LoLP), a reliability index which in this study is taken to be a measure of the probability the system will be unavailable due to inadequate generation.

$$
\text { LoLP }=\frac{\sum \text { outages }}{T_{S}}
$$

where $T_{S}$ is the total simulation time.

From the LoLP the Loss of Load Expected (LoLE) can be calculated for a time period, usually 1 year ( 8760 hours). The LoLE is another reliability measurement [23] which estimates how many hours in a time period the load will be lost.

$$
L o L E=L o L P * t
$$

where $\mathrm{t}$ is the time period being calculated for, in hours. 
The capacity factor (CF) of the WTG is a measure of the WTG's productivity; the ratio of the average power generated to the rated power output (Pr) of the WTG as follows:

$$
C F=\frac{E}{P r * t}
$$

where $\mathrm{t}$ is the time period being calculated for, in hours, $\mathrm{Pr}$ is the rated power output of WTG and E is the energy supplied for $\mathrm{t}$.

\section{B. Economic Analysis}

The cost of an ESS comprises of the capital cost; the operation and maintenance (O\&M) costs; and the cost of capital set by the loan interest rate (i). The capital cost is technology-specific and is comprised of the cost $\left(J_{P}\right)$ of charge/discharge power capacity $\left(P_{E S S}\right)$ and the cost $\left(J_{E}\right)$ of energy storage capacity $\left(E_{E S S}\right)$. The total annualised cost $\left(J_{E S S}\right)$ of the ESS can be calculated using (7).

$$
J_{E S S}=J_{\text {Capital }}+J_{O \& M}
$$

where $J_{\text {Capital }}$ is the annualized cost given by (8) and $J_{O \& M}$ is the annual operation and maintenance costs given by (11).

$$
J_{\text {Capital }}=T C C * C R F
$$

where the Total Capital Cost (TCC) is given by (9) and the Capital Recovery Factor (CRF) given by (10).

$$
\begin{gathered}
T C C=J_{P} * P_{E S S}+J_{E} * E_{E S S} \\
C R F=\frac{i(1+i)^{T}}{(1+i)^{T}-1}
\end{gathered}
$$

where $i$ is the interest rate and $\mathrm{T}$ is the lifetime, of the ESS.

The annual operation and maintenance (O\&M) costs are comprised of the fixed O\&M cost $\left(J_{F O \& M}\right)$ which is based on the ESS' power capacity $\left(\mathrm{P}_{\mathrm{ESS}}\right)$ and the variable operating cost $\left(J_{V O \& M}\right)$ which is based on the ESS' energy capacity (ESS) and the number of cycles (n).

$$
J_{O \& M}=J_{F O \& M} * P_{E S S}+J_{V O \& M} * n * E_{E S S}
$$

Following the procedure in section III.C, (3) and (7) are used to find the optimum ESS energy storage capacity to give the minimum overall system cost $(\mathrm{J})$ as described by (12), the objective function.

$$
\min (J)=\min \left(J_{E S S}+V_{o L L}\right)
$$

\section{Simulation and Analysis Procedure}

1. Prepare data: Load profile, wind speed data, WTG and CCDF.

2. Run MCS with zero ESS capacity and with a load that can always absorb the full WTG rated power. From this calculate the capacity factor of WTG using (6).

3. Use capacity factor to calculate the maximum average load WTG could supply for the year at a chosen wind power penetration) and hence the peak load value to be used for the given load profile.

4. To observe the outage durations expected in the system, run the MCS with zero ESS capacity and generate a distribution of outage duration lengths. Use outage duration distribution to identify most appropriate ESS technologies.

5. Now run MCS with various amounts of ESS capacity and with the calculated peak load (14). Use the efficiency values for the chosen ESS technology. Obtain results for VoLL (3) and LoLP (4) for each ESS capacity amount simulated.

6. Use VoLL and ESS capacity in economic analysis to calculate overall costs using ESS technology-specific costs with (7).
7. Repeat steps 5 and 6 until overall cost reaches a low point and starts to increase.

8. If desired, the analysis can be continued with increasing amounts of ESS capacity to show the relationship more accurately between ESS capacity and LoLP.

9. If desired, the analysis can be continued by restarting at step 4 but with a higher wind power penetration value. To do this, simply increase the load by the same increase as the wind power penetration level.

\section{CASE STUDY}

This case study is of a rural area in County Kerry, Ireland where there is some of the most wind power capacity in the country but also has some of the weakest networks [1]. The level of wind penetration (WP) is taken to be $60 \%$. Ireland's Transmission System Operator, EirGrid, indicated that up to $60 \%$ wind penetration could be achieved before system stability is affected [24].

For the wind speed model the last 30 years (1990-2020) of hourly wind speed data, measured at 10 metres height, were obtained from a rural weather observatory in County Kerry, Ireland [25]. The data were then adjusted to the hub height of the model WTG using (1).

The WTG data for the model in this simulation were obtained from the specifications of the 2.3 MW Enercon E82 E2 WTG used in Knockaneden wind farm which is less than $10 \mathrm{~km}$ from the weather observatory.

\section{A. Characterising the System}

From steps 1-2 the capacity factor $(\mathrm{CF})$ was calculated using (6) to be $31 \%$. The average load $\left(\mathrm{P}_{\text {ave }}\right)$ that the WTG could supply was derived from the CF of the WTG as follows:

$$
\begin{gathered}
P_{\text {ave }}=\operatorname{Pr} * \frac{C F}{100} * \frac{W P}{100} \\
P_{\text {peak }}=\frac{P_{\text {ave }}}{L F}
\end{gathered}
$$

where $L F$ is the load factor (ratio of average load demand to peak load demand) of the modelled load profile and WP in the percentage wind penetration in the system which is initially $60 \%$ in this case study.

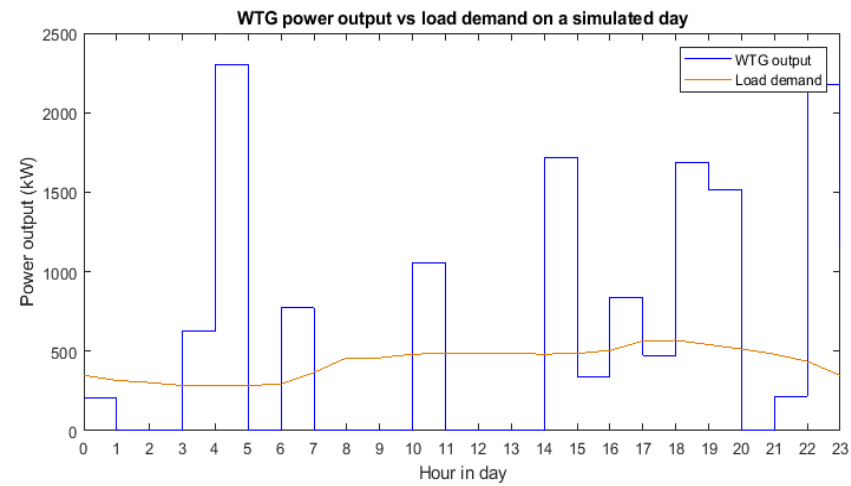

Fig. 2. Hourly WTG output versus demand on a simulated day

An example of the operation of the simulated system for a day is shown in Fig. 2. The ESS should ideally absorb the power during periods of excess, store this excess energy and then provide power to compensate for the WTG output during periods of deficit. In Fig. 2 it can be seen that for some hours, e.g. hours $8 \& 9$, that the WTG output has dropped to zero leaving a deficit of around $500 \mathrm{~kW}$. This is where the ESS should compensate using the excess energy stored from previous hours, e.g. hour 4 , to supply the load. The seasonal 
variation of wind power generation, Fig. 3, indicates that power deficits are more likely to occur in the summer months and less likely in the winter months.

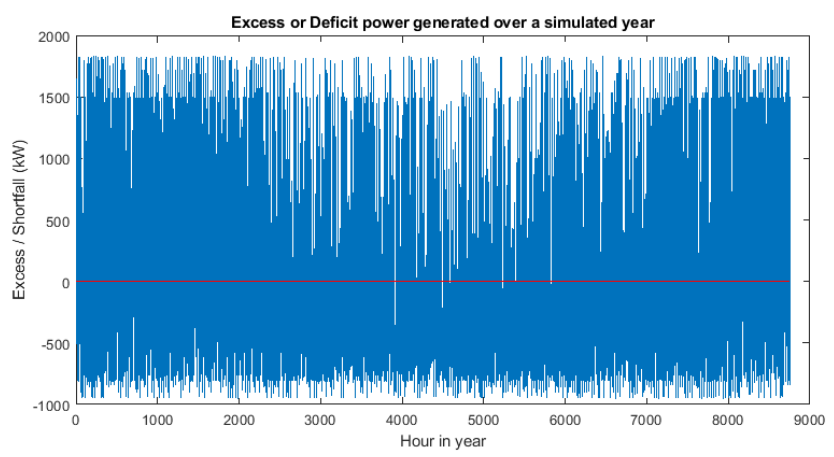

Fig. 3. Seasonal variation of power excess/deficit

Using the calculated $\mathrm{CF}$, the durations of power outages was shown to decay exponentially. This indicates there is likely a need for multiple-hours storage capacity in a system with $60 \%$ wind penetration. Above-ground Compressed Air Energy Storage (CAES) was identified as being suitable. The CAES technical data from [26-29] are given in Table III.

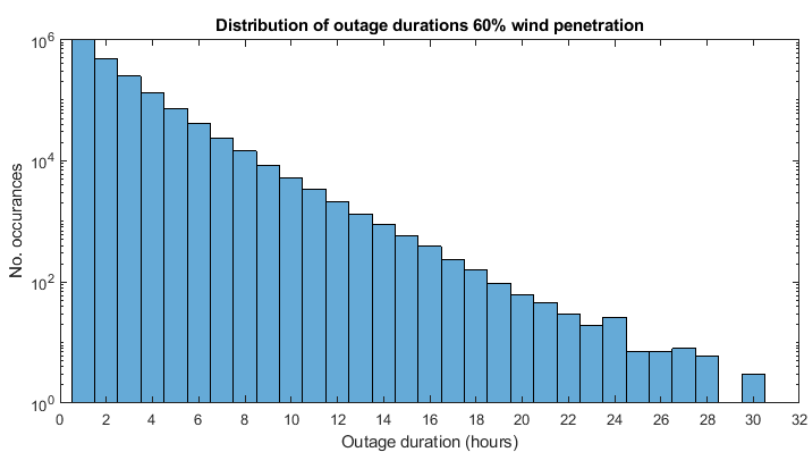

Fig. 4. Histogram of outage durations; log scale, 1000 years simulated

TABLE III. ABOVE-GRound CAES TeChNicAl Data

\begin{tabular}{|c|c|c|c|}
\hline $\begin{array}{c}\text { Power Range } \\
\text { (MW) }\end{array}$ & $\begin{array}{c}\text { Discharge } \\
\text { Time (hours) }\end{array}$ & $\begin{array}{c}\text { Round-trip } \\
\text { Efficiency (\%) }\end{array}$ & $\begin{array}{c}\text { Lifetime } \\
\text { (years) }\end{array}$ \\
\hline $1-500$ & $1-24+$ & $40-60$ & $25-40$ \\
\hline
\end{tabular}

\section{B. Optimising ESS Capacity}

In this case study the loan interest rate is set at $6 \%$. The low end of the ESS expected lifetime was used as a worst-case scenario. The values for the costs of the CAES system, shown in Table IV, were used with (8) to (11) to calculate the annualised cost of the ESS (7) as seen in Table V. Then the VoLL was calculated using (3). The power capacity of the ESS $\left(P_{E S S}\right)$ was calculated as follows:

$$
P_{E S S}=P_{r}-P_{\text {min load }}
$$

TABLE IV. MODEL ESS TECHNO-ECONOMIC DATA

\begin{tabular}{|c|c|c|c|c|c|c|}
\hline \multicolumn{7}{|c|}{ ESS Model: Above-ground CAES [29] } \\
\hline $\begin{array}{c}\text { Capacity } \\
\text { Cost } \\
(\epsilon / k W)\end{array}$ & $\begin{array}{c}\text { Capacity } \\
(\mathrm{kW})\end{array}$ & $\begin{array}{c}\text { Energy } \\
\text { Cost } \\
(\epsilon / k W h)\end{array}$ & $\begin{array}{c}\text { Fixed } \\
\text { O\&M } \\
(\epsilon / k W y r)\end{array}$ & $\begin{array}{c}\text { Variable } \\
\text { O\&M } \\
(\boldsymbol{E} / \boldsymbol{k W h y r})\end{array}$ & $\begin{array}{l}\text { Round-trip } \\
\text { Efficiency } \\
\text { (\%) }\end{array}$ & $\begin{array}{l}\text { Life- } \\
\text { time } \\
\text { (years) }\end{array}$ \\
\hline 846 & 1921 & 110 & 2.2 & 0.0022 & 60 & 25 \\
\hline
\end{tabular}

TABLE V. ENERgy Storage SyStem Costing

\begin{tabular}{|c|c|c|c|c|c|}
\hline $\begin{array}{c}\text { Capacity } \\
\text { ESS } \\
(\boldsymbol{M W h})\end{array}$ & $\begin{array}{c}\text { No of } \\
\text { Cycles }\end{array}$ & $\begin{array}{c}\boldsymbol{J}_{\text {capital }} \\
(\boldsymbol{k} \boldsymbol{\epsilon})\end{array}$ & $\begin{array}{c}\boldsymbol{J}_{\boldsymbol{F O} \& \boldsymbol{M}} \\
(\boldsymbol{k} \boldsymbol{\epsilon})\end{array}$ & $\begin{array}{c}\boldsymbol{J}_{\text {Vo\&M }} \\
(\boldsymbol{k} \boldsymbol{)}\end{array}$ & $\begin{array}{c}\boldsymbol{J}_{\text {ESS }} \\
(\boldsymbol{k} \boldsymbol{\epsilon})\end{array}$ \\
\hline 1 & 2266 & 135.74 & 4.23 & 4.99 & 144.95 \\
\hline 2 & 1426 & 144.34 & 4.23 & 6.28 & 154.84 \\
\hline 4 & 799 & 161.55 & 4.23 & 7.03 & 172.81 \\
\hline 6 & 550 & 178.76 & 4.23 & 7.27 & 190.26 \\
\hline 8 & 419 & 195.97 & 4.23 & 7.38 & 207.57 \\
\hline
\end{tabular}

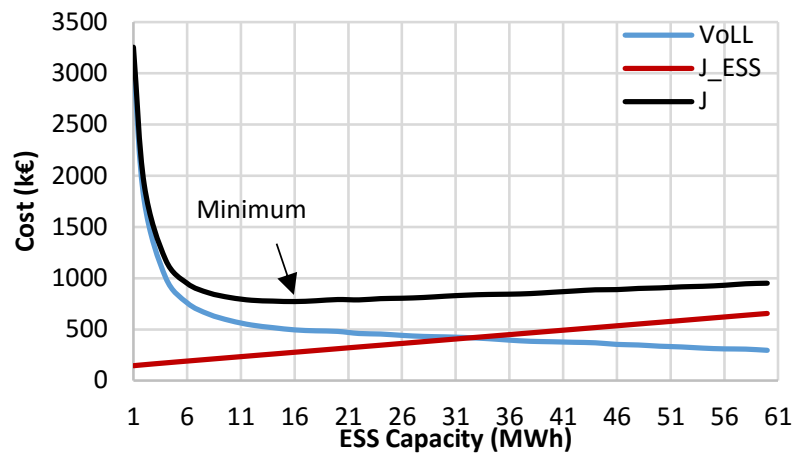

Fig. 5. Minimising overall system costs (J)

A section of the results is presented in Table VI, it shows the minimum value for the overall system costs occurring at an ESS capacity of $16 \mathrm{MWh}$ as marked in bold. Larger ESS capacities were tested and as expected the overall cost continues to rise with ESS capacity as seen in Fig. 5.

TABLE VI. Minimising System Cost Results

\begin{tabular}{|c|c|c|c|}
\hline \multicolumn{4}{|c|}{ Costs for network with 60\% WP \& $\mathbf{P}_{\text {EsS }}$ of $1921 \mathbf{k W}$} \\
\hline $\begin{array}{c}\text { Capacity } \\
\text { ESS }(\boldsymbol{M W h})\end{array}$ & VoLL $(\boldsymbol{k} \boldsymbol{\epsilon})$ & $\boldsymbol{J}_{\boldsymbol{E S S}}(\boldsymbol{k} \boldsymbol{\epsilon})$ & $\boldsymbol{J}(\boldsymbol{k} \boldsymbol{\epsilon})$ \\
\hline 0 & $7,417.37$ & 0 & $7,417.37$ \\
\hline 8 & 649.04 & 207.57 & 856.62 \\
\hline $\mathbf{1 6}$ & $\mathbf{4 9 4 . 8 5}$ & $\mathbf{2 7 6 . 5 7}$ & $\mathbf{7 7 1 . 4 2}$ \\
\hline 24 & 454.55 & 345.46 & 800.01 \\
\hline
\end{tabular}

\section{Improving Reliability}

The LoLE for the optimum ESS capacity of 16MWh identified was calculated, using (5), to be 311.07 hours/year. In Ireland, the TSO EirGrid considers 8 hours/year to be an acceptable standard for LOLE on a system [24]. So, the analysis was extended to show increased reliability with increasing ESS capacity as seen in Fig. 6. It was found that to meet the LOLE standard, 150 MWh ESS capacity is needed.

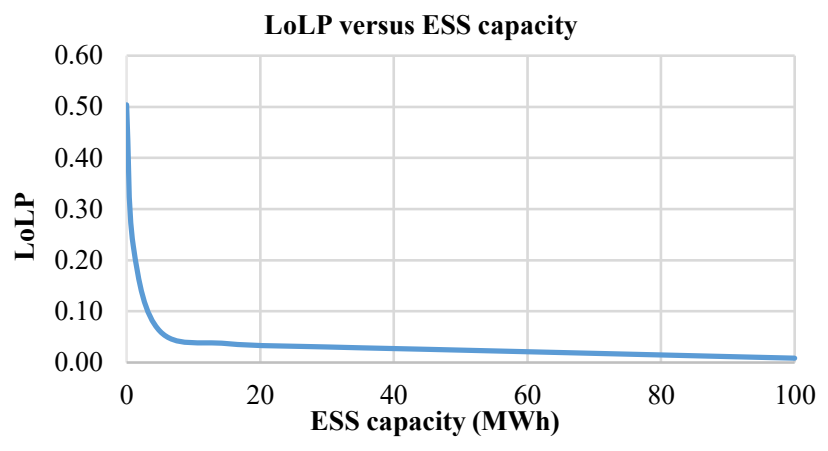

Fig. 6. Improving reliability; LoLP vs. ESS capacity

\section{DISCUSSION}

The case study demonstrated that the wind speed, load and WTG models used in the Monte Carlo Simulation (MCS) yields satisfactory results. The capacity factor for the system without any ESS capacity was found to be approximately $31 \%$. According to the Irish Wind Energy Association 31\% is the average expected capacity factor for a WTG in Ireland [30]. The seasonal variation of wind power generation, Fig. 3, shows power deficits are more likely to occur in the summer months and less likely in the winter months. This shows the merit of the probabilistic modelling using Weibull distributions for each hour of the year to capture the correlation between subsequent hours' wind speeds. Though it should be noted that this technique does increase the simulation time when compared to using a single Weibull distribution to model the wind. 


\section{A. Selecting the ESS Technology}

The histogram of outage durations in Fig. 4 showed that short duration outages ( 1 hour) were the most frequent and the frequency of longer outage durations decreased exponentially with increasing duration. Still, the need for multiple hours of storage was apparent. The full suite of applicable ESS technologies can be seen in [29].

The technology that was investigated in this case study, Compressed Air Energy Storage (CAES) is widely examined for wind power applications. It was chosen because its' storage capacity can be scaled independently of its' power capacity. The above-ground CAES does not require any special geological features and is a developed technology according to [29].

\section{B. Optimum ESS}

The optimum ESS capacity to minimise the overall system costs was found to be $16 \mathrm{MWh}$. Considering that in this case study the average load is approximately $430 \mathrm{~kW}, 16 \mathrm{MWh}$ of ESS capacity translates to a store of energy required to deliver the average load power demand for 37.2 hours in an extreme case. Yet even this level of storage capacity would mean that without additional operating reserves in the system, the LOLE (311.07 hours/year) would exceed acceptable levels. The 150MWh of ESS capacity needed to meet the LOLE standard translates to a store of energy required to deliver the average load power demand for approximately 350 hours in an extreme case. This level of storage has not been achieved commercially as indicated by the literature [26-29].

\section{Cost-Benefit Analysis}

While the optimum ESS capacity to minimise the overall system costs has been found, the economic viability of the ESS in this case study could be assessed by considering the economic benefit of reducing the annual VoLL by introducing the ESS against the cost of adding the ESS. This Reduction in VoLL $\left(R_{V O L L}\right)$ can be calculated by the difference between the VoLL without storage $\left(V o L L_{0}\right)$ and the VoLL with storage as follows:

$$
R_{V O L L}=V o L L_{0}-V o L L
$$

From this the economic benefit $\left(r_{e s s}\right)$ of reducing the annual VoLL can be expressed as a percentage of the annualised cost of the ESS ( $\left.J_{E S S}\right)$ as follows:

$$
r_{E S S}=100 * \frac{R_{V O L L}}{J_{E S S}}
$$

\begin{tabular}{|c|c|c|c|c|}
\hline $\begin{array}{c}\text { Capacity } \\
\text { ESS }(M W h)\end{array}$ & $\begin{array}{c}\text { VoLL } \\
(k \epsilon)\end{array}$ & $\begin{array}{c}R_{\text {VoLL }} \\
(\boldsymbol{k} \boldsymbol{\epsilon})\end{array}$ & $\begin{array}{c}J_{E S S} \\
(\boldsymbol{k} \boldsymbol{\epsilon})\end{array}$ & $\begin{array}{l}r_{\text {ess }} \\
(\%)\end{array}$ \\
\hline 0 & $7,410.69$ & 0.0 & 0.00 & - \\
\hline 1 & $3,110.01$ & $4,300.69$ & 144.95 & $2,967.04$ \\
\hline 5 & 849.50 & $6,561.19$ & 181.57 & $3,613.62$ \\
\hline 150 & 11.75 & $7,398.94$ & $1,430.10$ & 517.37 \\
\hline
\end{tabular}

TABLE VII. COST - BENEFIT ANALYSIS OF ESS

This was calculated for the full range of ESS capacity values simulated; a section of results is shown in Table VII with the greatest benefit marked in bold. The benefits $\left(r_{E S S}\right)$ were shown to be orders of magnitude higher than the cost of the ESS $\left(J_{E S S}\right)$ which is contrary to the expected findings [23]. The data available for the CCDF used to calculate the VoLL are not as well understood and no Irish-specific data could be found. Further, additional analysis is done in Section V.D to better understand the economic viability of implementing the ESS. Even if the VoLL is overvalued, if the VoLL is reduced linearly the optimum ESS capacity will remain the same; only the economic viability of the project will be impacted.

\section{Levelized Cost of Storage}

The Levelized Cost of Storage (LCoS) indicates what price $(€ / \mathrm{MWh})$ the electricity being stored in the ESS would need to be sold for to cover the cost of the ESS. Assuming that the cost of the excess WTG electricity used to charge the ESS is negligible, as this energy would otherwise be curtailed, the LCoS can be calculated as follows:

$$
L C o S=1000 * \frac{J_{E S S}}{E_{E S S} * \frac{n}{2} * \eta_{r t}}
$$

where $J_{E S S}$ is the annualised total cost of the ESS ( $€$ ), $E_{E S S}$ is the capacity of the ESS ( $\mathrm{kWh}), \eta_{\mathrm{rt}}$ is the round-trip efficiency and $n$ is the annual number of cycles which is then divided by two to give the number of discharge cycles.

The optimum ESS capacity to minimise the LCoS is marked in bold and found to be $3 \mathrm{MWh}$. The values of LCoS in Table VIII may be achieved if the ESS participates in the imbalance market in which case an ESS technology with a fast demand response time, such as batteries, should be examined.

TABLE VIII. LEVELIZED COST OF STORAGE

\begin{tabular}{|c|c|c|c|}
\hline $\begin{array}{c}\text { Capacity } \\
\text { ESS }(\boldsymbol{M W h})\end{array}$ & No of Cycles & $\begin{array}{c}\boldsymbol{J}_{\boldsymbol{E S S}} \\
(\boldsymbol{k} \boldsymbol{\epsilon})\end{array}$ & $\begin{array}{c}\boldsymbol{L C o S}^{\boldsymbol{a}} \\
(\boldsymbol{\epsilon} / \boldsymbol{M W h})\end{array}$ \\
\hline 1 & 2266 & 144.95 & 215 \\
\hline $\mathbf{3}$ & $\mathbf{1 0 3 0}$ & $\mathbf{1 6 3 . 9 7}$ & $\mathbf{1 7 8}$ \\
\hline 16 & 213 & 276.56 & 272 \\
\hline 50 & 70 & 569.30 & 547 \\
\hline 150 & 24 & \multicolumn{3}{|c|}{$1,430.10$} & 1321 \\
\hline \multicolumn{4}{|c}{ a Round trip efficiency $\left(\eta_{\mathrm{rt}}\right)$ is $60 \%$}
\end{tabular}

\section{CONCLUSION}

The Monte Carlo simulation is performed using real data in a case study of a rural area in County Kerry, Ireland. The probabilistic wind speed model of 30 years of historical wind speed data, used in the Monte Carlo Simulation (MCS) captured the seasonal variation of the wind. The WTG capacity factor was found to be the same as the national average for WTGs; $31 \%$. By considering the distribution of outage duration lengths, above-ground CAES was chosen.

The system reliability was shown to increase with ESS capacity. It was found that the ESS capacity needed for reliable operation with $60 \%$ wind penetration is $150 \mathrm{MWh}$ which translates to a store of energy required to deliver the average load power demand for approximately 350 hours in an extreme case. As this level of storage is not found commercially, the need for a carbon-free energy sources complementary to wind was indicated. Such sources may be intermittent sources such as solar or wave energy or baseload carbon-free sources such as hydro or nuclear.

The Value of Lost Load was used to optimally size the ESS capacity to minimise the overall system cost. The optimal ESS capacity was found to be $16 \mathrm{MWh}$ which translates to a store of energy required to deliver the average load power demand for 37.2 hours in an extreme case. The need for accurate and network-specific data when assessing the VoLL is highlighted. It was determined that further analysis in the form of a Levelized Cost of Storage ( $\mathrm{LCoS}$ ) should be done.

The LCoS was calculated for the optimally sized level of storage (16MWh) and for the level of storage required to make wind power generation reliable (150MWh) to be $€ 272 / \mathrm{MWh}$ and $€ 1321 / \mathrm{MWh}$ respectively. These values are not costcompetitive if they are to compete with conventional generation sources participating in the wholesale electricity market. 


\section{REFERENCES}

[1] A. Keane and M. O'Malley, "Optimal allocation of embedded generation on distribution networks," IEEE Transactions on Power Systems, vol. 20, no. 3, pp. 16401646, August 2005.

[2] PB Power, "Costs and benefits of embedded generation in Ireland," SEAI, Dublin, 2004.

[3] P. Denholm, E. Ela, B. Kirby and M. Milligan, "Role of Energy Storage with Renewable Electricity Generation," Golden, CO (United States), 2010.

[4] EirGrid, SONI, "Winter Outlook 2017/18," EirGrid, 2018.

[5] A. B. Gallo, J. R. Simões-Moreira, H. K. Costa, M. M. Santos and E. Moutinho dos Santos, "Energy storage in the energy transition context: A technology review, " vol. 65, Elsevier Ltd, 2016, pp. 800-822.

[6] J. P. Barton and D. G. Infield, "Energy storage and its use with intermittent renewable energy," IEEE Transactions on Energy Conversion, vol. 19, no. 2, pp. 441-448, July 2004.

[7] M. C.Argyrou, P. Christodoulides and S. A. Kalogirou, "Energy storage for electricity generation and related processes: Technologies appraisal and grid scale applications," Renewable and Sustainable Energy Reviews, vol. 94, pp. 804-821, 2018.

[8] C. A. and G. D. F., "Grid-scale energy storage applications in renewable energy integration: A survey," Energy Conversion and Management, pp. 885-894, November 2014

[9] A. Gonzalez-Garrido, A. Saez-De-Ibarra, A. Milo, H. Gaztanaga and P. Eguia, "Techno-economic assessment of energy management strategies for a renewable portfolio with storage systems in energy and frequency reserve markets," in International Conference on the European Energy Market, EEM, 2019.

[10] D. G. Choi, D. Min and J.-h. Ryu, "Economic Value Assessment and Optimal Sizing of an Energy Storage System in a Grid-Connected Wind Farm," Energies, vol. 11, pp. 591-600, 2018.

[11] P. Wang and R. Billinton, "Time-sequential simulation technique for rural distribution system reliability cost/worth evaluation including wind generation as alternative supply," IEE Proceedings - Generation, Transmission and Distribution, vol. 148, no. 4, pp. 355 - 360, 2001.

[12] S. W. Alnaser and L. F. Ochoa, "Optimal Sizing and Control of Energy Storage in Wind Power-Rich Distribution Networks," IEEE Transactions on Power Systems, vol. 31, no. 3, pp. 2004-2013, June 2016.

[13] J. C. Wen-Hui Shi, "Reliability Assessment of Interconnected Generation Systems Based on Hourly Wind Speed Probability Model," Energy Procedia, pp. 819-827, 2011.

[14] A. D. W. John W. Twidell, Renewable Energy Resources, London: Taylor\&Francis Group, 2006.

[15] Y. Kifle, B. Khan and P. Singh, "Assessment and Enhancement of Distribution System Reliability by Renewable Energy Sources and Energy Storage," Journal of Green Engineering, vol. 8, no. 3, pp. 219 $262,2018$.
[16] L. Bertling, P. Bangalore and L. A. Tuan, "On the use of reliability test systems: A literature survey," in IEEE Power and Energy Society General Meeting, Detroit, 2011.

[17] F. Chen, F. Li, Z. Wei, G. Sun and J. Li, "Reliability models of wind farms considering wind speed correlation and WTG outage," Electric Power Systems Research, vol. 119, pp. 385-392, 2015.

[18] G. Celli, F. Pilo, G. Pisano and G. G. Soma, "Optimal operation of active distribution networks with Distributed Energy Storage," in 2012 IEEE International Energy Conference and Exhibition, ENERGYCON 2012, 2012

[19] J. A. Martinez, F. De Léon, A. Mehrizi-Sani, M. H. Nehrir, C. Wang and V. Dinavahi, "Tools for analysis and design of distributed resources-Part II: Tools for planning, analysis and design of distribution networks with distributed resources," IEEE Transactions on Power Delivery, vol. 26, no. 3, pp. 1653-1662, July 2011.

[20] R. Billinton and S. Jonnavithula, "A Test System For Teaching Overall Power System Reliability Assessment," IEEE Transactions on Power Systems, vol. 11, no. 4, pp. 1670-1676, November 1996.

[21] R. Billinton, S. Kumar, N. Chowdhury, K. Chu, K. Debnath, L. Goel, E. Khan, P. Kos, G. Nourbakhsh and J. Oteng-Adjei, "A Reliability Test System for Educational Purposes," IEEE Transactions on Power Systems, vol. 4, no. 3, pp. 1578 - 1583, August 1989.

[22] A. Jonnavithula and R. Billinton, "Features that influence composite power system reliability worth assessment," IEEE Transactions on Power Systems, vol. 12, no. 4, pp. 1536 - 1541, November 1997.

[23] R. Zheng and J. Zhong, "Generation Adequacy Assessment for Power Systems with Wind Turbine and Energy Storage," in 2010 Innovative Smart Grid Technologies (ISGT), Gothenburg, 2010.

[24] EirGrid, "All Island Tso Facilitation of Renewables studies," EirGrid, Dublin, 2010.

[25] M. Eireann, "Historical Data," 2020. [Online]. Available: https://www.met.ie/climate/availabledata/historical-data. [Accessed 0505 2020].

[26] H. Chen, T. N. Conga, W. Yang, C. Tan, Y. Li and Y. Ding, "Progress in electrical energy storage system: A critical review," Progress in Natural Science, vol. 19, no. 3, pp. 291-312, 2009.

[27] F. Díaz-González, A. Sumpera, O. Gomis-Bellmunta and R. Villafáfila-Robles, "A review of energy storage technologies for wind power applications," Renewable and Sustainable Energy Reviews, vol. 16, no. 4, pp. 2154-2171, 2012.

[28] H. Zhao, Q. Wu, S. Hu, X. Honghua and C. N. Rasmussen, "Review of energy storage system for wind power integration support," Applied Energy, vol. 136, no. 1, pp. 545-553, 2015.

[29] S. S. Behnam Zakeri, "Electrical energy storage systems: A comparative life cycle cost analysis," Renewable and Sustainable Energy Reviews, vol. 42, pp. 569-596, 2015 